\title{
Psychiatric Emergency Service - An Analysis of a Hospital in Northern Portugal
}

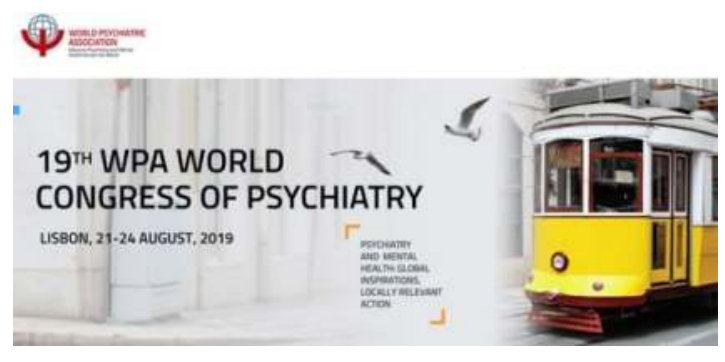

\author{
C. Campos ${ }^{1}$, S. Carneiro ${ }^{1}$, J. Mesquita ${ }^{1}$, S. Azenha ${ }^{1}$
}

${ }^{1}$ Hospital de Braga, Department of Psychiatry and Mental Health, Braga, Portugal

Background: The Psychiatric Emergency Service (PES) aims to provide urgent care to serious clinical situations, which means handling psychotic outbreaks, manic episodes, suicidal ideation/attempt, severe behavioral changes, among other situations that put the patient or those who surround him in danger, or that induce significant acute suffering. However, according to our clinical experience, since access to the PES is easy, it is found that patients often resort without a valid reason, by themselves of referred by another physician, which hinders the proper functioning of the PES. For a variety of reasons the number of emergency patients is on the rise, which makes the overcrowding of the PES with non-urgent or non-psychiatric cases even more problematic, compromising the good patient care for those who really need it.

Objectives: The aim of this work is to make a demographic and clinical characterization of a random sample of patients that attended to the PES of Hospital de Braga, as well as verify the percentage of real emergencies and analyze the reasons to resort to the PES.

Materials and Methods: Consultation of the clinical information of a random sample of emergency episodes in the PES of Hospital de Braga during the last 3 months of year 2018. The clinical information of a total of 232 emergency episodes were collected.

Results:

Sociodemographic and clinic variables: $\mathrm{N}=232$

\begin{tabular}{|c|c|c|}
\hline Gender & $\begin{array}{ll}\text { - } & \text { Female }-\mathbf{6 1 , 2} \% \\
\text { - } & \text { Male }-\mathbf{3 8 , 8} \% \\
\end{array}$ & Percentage of justified and unjustified resort to the PES \\
\hline Mean age & - 47,7 years & \\
\hline $\begin{array}{l}\text { Priority of } \\
\text { assistance }\end{array}$ & $\begin{array}{ll}\text { - } & \text { Very Urgent - } 27,1 \% \\
\text { - } & \text { Urgent - } 67,7 \% \\
\text { - } & \text { Slightly Urgent - 5,2\% }\end{array}$ & \\
\hline $\begin{array}{l}\text { Reasons to resort } \\
\text { to the PES }\end{array}$ & 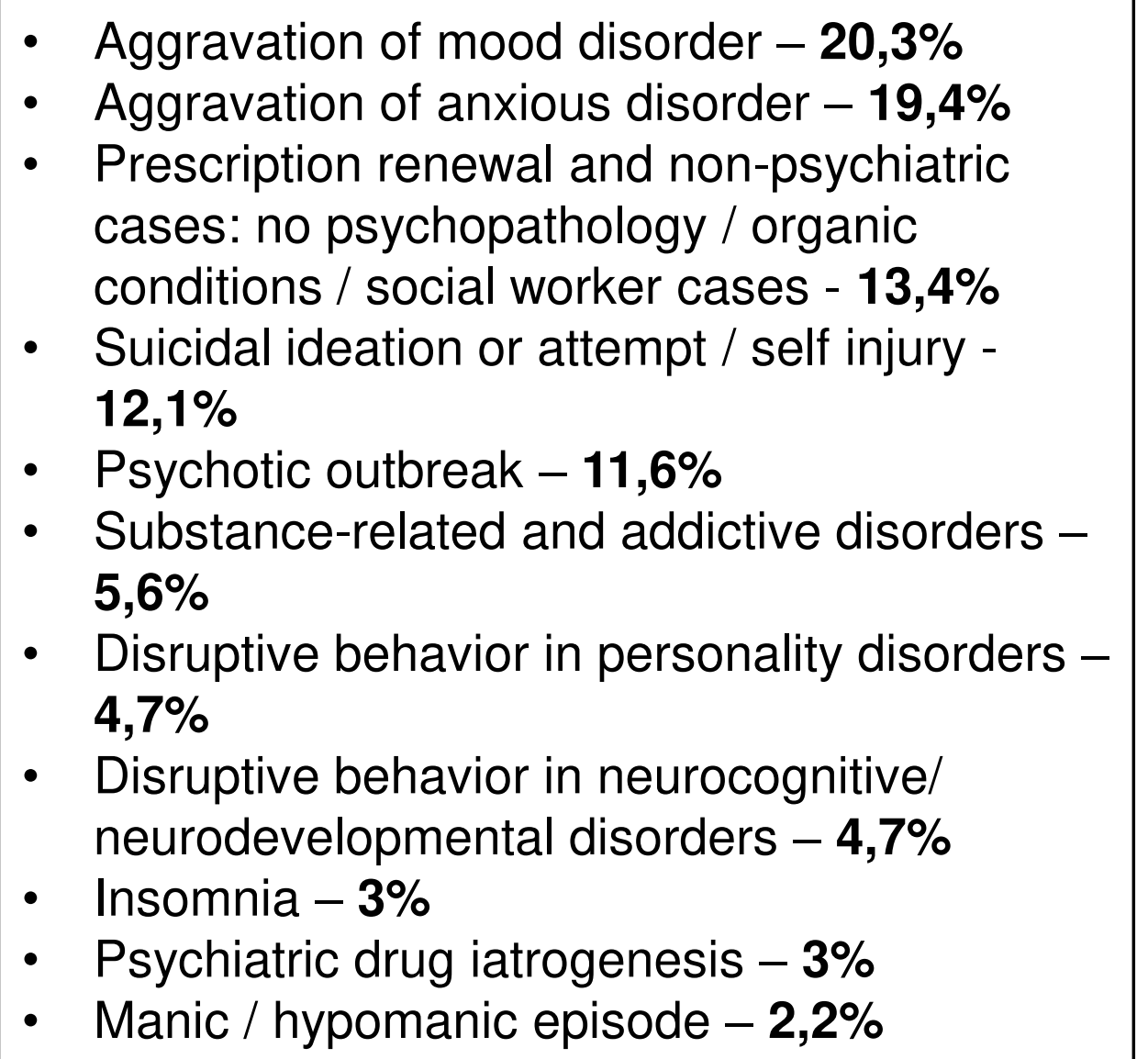 & $\begin{array}{l}54,7 \% \\
\text { Justified resort to the PES } \\
\text { Unjustified resort to the PES }\end{array}$ \\
\hline $\begin{array}{l}\text { Referral initiative } \\
\text { to the PES }\end{array}$ & $\begin{array}{l}\text { - } \text { Oneself - } \mathbf{4 5 , 7 \%} \\
\text { - } \text { Non-psychiatric physicians - } \mathbf{2 5 , 4 \%} \\
\text { - } \text { Family members / caregivers - } \mathbf{1 8 , 5 \%} \\
\text { - } \text { Emergency Services / Community Services / } \\
\text { Public Health Services - } \mathbf{7 , 8 \%} \\
\text { - } \\
\text { Psychiatrists - } \mathbf{2 , 6 \%}\end{array}$ & $\begin{array}{l}\text { - Oneself - } \mathbf{4 0 , 6 \%} \\
\text { - } \text { Non-psychiatric physicians - } \mathbf{5 2 , 5 \%} \\
\text { - } \text { Family members / caregivers - } \mathbf{7 4 , 4 \%} \\
\text { - Emergency Services / Community Services / } \\
\text { Public Health Services - } \mathbf{8 3 , 3 \%} \\
\text { - Psychiatrists - } \mathbf{1 0 0 \%}\end{array}$ \\
\hline
\end{tabular}

Conclusions: In our sample $45,3 \%$ of the patients who resorted to the PES did it incorrectly, which is sadly a remarkable percentage. The third most frequent reason for coming to the PES were non-psychiatric conditions, as well as social worker cases and prescription renewals of psychiatric medication, which obviously should be done elsewhere. Most people using PES incorrectly made that decision themselves, however only $52,6 \%$ of patients referred by non-psychiatric physicians were correctly sent to the PES. Most unwarranted medical referrals to PES were related to non-psychiatric disturbances or mood and anxious symptoms that should be handled in other clinical services. In what concerns the wrong resort by self-recreation, most of the cases were related to anxious symptoms. The improper resort to the PES entails monetary and human resources costs that end up limiting its access to the patients who really need it. As we could note, very frequently are the patients themselves and, more severely, the non-psychiatric physicians who end up referring the patients unduly, which ends up denouncing the lack of mental health literacy by doctors of other specialties. It is important to clarify both the population and the non-psychiatric physicians about the actual psychiatric referral criteria in order to optimize the existing resources.

Sources: 1 - Sadock, Benjamin J., Virginia A. Sadock, and Pedro Ruiz. Kaplan \& Sadock's Synopsis of Psychiatry: Behavioral Sciences/clinical Psychiatry. 11th ed. Philadelphia: Wolters Kluwer, 2015. 